\title{
Types of Sedimentary Facies of Palace Area in Songliao Basin
}

\author{
ZOU Jiaqi ${ }^{1,}$ a, WANG Wenguang, ${ }^{2, b}$,LIU Chengzhi ${ }^{3, \text { c }}$ \\ ${ }^{1}$ Northeast Petroleum University of Daqing City, Heilongjiang \\ province in China \\ ${ }^{2}$ Northeast Petroleum University of Daqing City, Heilongjiang \\ province in China \\ ${ }^{2}$ Northeast Petroleum University of Daqing City, Heilongjiang \\ province in China

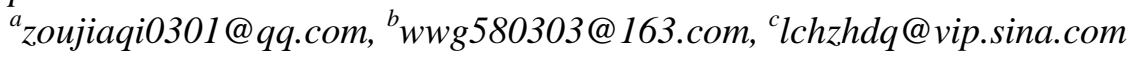

\begin{abstract}
The palace is located in the Songliao Basin, southeast regional uplift Palace rift, Denglouku off during the deposition of Au transition period for the basin, with more than provenance, short distance transport, Tianpingbuqi characteristics, Quantou deposition during the period of depression basin, with settlement rate, stable sedimentary environment and so on. According to the results of previous research and heavy mineral analysis to determine the palace area Denglouku Quantou northeast direction during the deposition source and southern elm Dehui subject matter - Fulongquan provenance affects two provenances, braided river Delta - meandering river depositional environment. Total identify four kinds of sedimentary facies, seven kinds subfacies and 14 types of sedimentary microfacies.
\end{abstract}

Keywords: Songliao Basin; palace rift; sedimentary facies

\section{1 braided river delta}

Braided river delta is braided into a stable flow of water (sea, lake) to form a coarse clastic delta. Seasonal water flow control or mountain river flows by its development. At the end of the alluvial fan and the side edge of the alluvial plain hill or mountain direct development of braided channel via a short distance or long distance transport can post directly into the water to form a stable braided 
river delta.

Based braided river delta sedimentary environment and sedimentary rocks color, composition, structure, structure, thickness, etc. deposited signs, and the phase is divided into braided river delta plain and braided river delta front, each sub phase also by a variety of micro-phase composition, such as braided river delta plain can be divided into braided channel, underwater distributary channel, underwater distributary channel and the shore sedimentary microfacies; braided river delta front can into underwater distributary channel, underwater distributary channel, mouth bar and front sheet sand sedimentary microfacies.

\section{1,A braided river delta plain}

Braided river delta plain can be divided into braided channel microfacies an d sedimentary microfacies constitute the shore, where the braided river sand is de posited in braided river delta plain facies of the main sand body.

2, braided river delta front

Braided river delta front sands are braided river delta region of the main san $\mathrm{d}$ deposited by underwater distributary channel, mouth bar, underwater distributa ry channel and front sheet sand between sedimentary microfacies constituted Asi a sandbody in lacustrine sediments reflect the characteristics of gray-black mudst one interlayer more. Located on both sides of underwater distributary channel, u nderwater river diversions are washed retained or deposited relatively fine-graine $\mathrm{d}$ material, the deposition of suspended sediments, lithology by dark mudstone, $\mathrm{s}$ ilty mudstone and silty mudstone components. Visible horizontal bedding and a s mall ripple bedding.

\section{2 meandering river with}

Palace area Quantou mainly meandering river deposits. Meandering river is characterized by a curved single channel, smaller than a braided river slope, deep river, wider than a small, portable detritus in bedload than small, relatively slow flow changes. Long and short-term low-level flooding still exists. The main type s of rocks: coarse sandstone, fine sandstone, siltstone, mudstone and green purpl e gray silty mudstone. 


\section{1,A riverbed subphase}

Riverbed is often part of the water of the river valley, which occupies the lo west part of the water level of the water. Its cross section was grooved, narrow $\mathrm{u}$ pstream and downstream wide bottom screen shows a clear erosion, fluvial depo sits constitute the base unit. Asia also known as the river bed with the underlying sub-sub-phase or phase. Its sandstone rock types, with minor conglomerate, rive $r$ debris particle phase is the thickest. Bedding development, types and colorful. Lack of animal and plant fossils, plants only see the broken branch, trunk and oth er debris, rock and more with a lenticular shape, the bottom of the screen with ob vious erosion. Riverbed further divided into sub-phase deposition and retention ri verbed Sedimentation two micro phase.

Palace area Quantou phase meandering river bed sub-phase, can be seen cle arly bed residence Sedimentation deposition $\rightarrow \rightarrow \rightarrow$ riverbed sedimentary depo sitional model stranded beach side deposition. Mainly as a pale yellow thick laye $r$ of sandstone, sandstone grain size varies with coarse sandstone and sandstone-b ased, mixed with several layers of thin conglomerate, with a typical multi-phase superposition characteristics. Rivers lateral accretion evident, while beach develo pment, with typical eclipse by a convex concave. Thick sandstone interior see lar ge tabular cross-bedding, the interface between the layer lines parallel to each ot her, the bottom of the visible surface erosion, meandering river point bar on the $\mathrm{p}$ ositive side of the laminated multi-cycle, showed a coarse grain size variation on the fine trend.

\section{2, bank subphase}

Bank deposit growth in the upper riverbed deposits, development outcroppi ng good crevasse splay and natural levee microfacies. Its rock type is simple, fin e-grained, with small cross-bedding based.

(1) levee

To form a thin interbedded sand and mud is characterized. Bottom-up devel opment of small-scale trough cross-bedding, wavy texture and level of cross-bed 
ding, calcareous concretions; monolayer thickness $0.5 \mathrm{~m} \sim 2.0 \mathrm{~m}$. The Springs sec tion of levee district sedimentary microfacies mainly as fuchsia and purple silty mudstone and siltstone interbedded shale, natural levee deposits visible Shangpa $\mathrm{n}$ bedding and trough cross-bedding, calcareous concretions development, reflect ing the apparent hiatus; mudstone visible cracking, reflected the prevailing clima te.

(2) splay

Crevasse splay in flood water sector deposits of natural levee broke on the fl oodplain formation. The study splay microfacies in light gray fine-grained sandst one and siltstone, visible small cross bedding and parallel bedding, lenticular, siz e thicker than the natural levee, with varying grain of sand-like structure, particle arrangement moderate poorly developed pore size distribution of the particles in terspersed; argillaceous with recrystallization, was filled in between the film-like particles were banded partial, lumpy, uneven distribution; carbonate lumps, fillin g voids, part microcrystalline carbonate was like, and silt mixed distribution.

(3) River Man Asian phase

Man River sub-phase is a sub-type of the plains with rivers, located outside the levee, where low-lying and flat, during the flood, the water overflowing levee, flow reduced, so that a large number of river suspended sediment accumulation. Because it is a result of flooding during vertical accretion of sediment, so called flood basins.

\section{Man River sub-phase}

Springs Man Asian section of river floodplain facies lake and river flood mi crofacies, mainly developed light gray sandstone, dark gray and dark gray mudst one, siltstone points, including carbonized plant fragments, developed parallel be dding and small cross-bedding.

(1). Floodplain

The deposit is located in the floodplain study fine sedimentary levee outside, mainly as muddy siltstone, mudstone and silty mudstone, color, mostly purple, 
fuchsia rare dark red, gray, cracked mud mudstone and calcareous concretions are very developed.

(2). Man River lakes

Man River lake sediments with claystone and siltstone appear there is a phase of the finest river sediment types. Arid climatic conditions, the water table dropped, rapid evaporation surface, often forming calcium and iron tuberculosis. In humid climates Man River lakes, biological and lush, rich in organic matter can form deposits and relatively intact animal and plant fossils. In drought areas, evaporation increases, Man River lakes can develop into Salt Lake, the formation of salt deposits.

\section{Bedding type and structure type}

(1).parallel to the bedding

Parallel bedding generally appear strong hydrodynamic conditions in the product water flow effect, non-static sedimentary environment in the study area springs period occurred mainly in Asia with braided river bed and river meandering river bed sedimentary micro sub-phase retention phase.

(2) cross-bedding

Cross-bedded sedimentary grounds caused by the flow of the medium, such as wind or water, which mainly reflects the traction current sedimentary environment. Springs for some strata are more common form of bedding, the general development in Asia with braided river bed sedimentary microfacies heart beach and meandering river embankment Asia sedimentary environments.

(3) wavy bedding

Wavy bedding by shock waves caused by the movement of the deposition medium, which reflects the volatility of the water environment and the way the water environment in the study area is a period of unusual springs bedding types. Mainly developed in the levee embankment subphase microfacies environment.

a, scour surface

Erosion surface by a sudden increase in fluid flow, erosion of the underlying sediment erosion and the formation of undulating surface. Often 
scour nearby boulder clay surface, often associated with graded bedding. In the study area, mainly in the Springs section of the river bed braided river bed sub-phases and sub-phases meandering river bed residence sedimentary facies micro environment.

b, erosion - packed structure

Scour - packed structure usually represents hiatus, the braided river systems and meandering river sedimentary system in the study area is more developed, scour the lower face mostly fine deposition, the deposition is usually coarser upper river glutenite.

C,slump structures In a period of slump structures visible

Springs formations, which mainly reflects the fluvial deposits of this type of sedimentary environments.

\section{Summary}

Quantou period, Songliao basin tectonic subsidence into the depression stag e, the entire Songliao Basin in an expansion phase, steady sedimentation basin, $\mathrm{d}$ evelopment of a river, shallow lakes, reservoirs deltaic sediments.

Development of shallow water delta distributary channel and underwater dis tributary channel sand bodies, constitute the entire region sand skeleton. Sand lat eral change quickly, stripe or intermittent stripes spread on a flat surface. Researc $\mathrm{h}$ Springs Sedimentary characteristics and change patterns drawn, Stephen went $\mathrm{t}$ hrough a period of deposition of meandering river shore shallow lake $\rightarrow \rightarrow$ braid ed river delta phase evolution. Because some springs during the deposition.

Songliao Basin in a relatively strong tectonic movement, steep terrain, dry c limate under the sedimentary environment, with a steady process of settlement in the basin sediment accumulation slows topography, sediment thickness increases , estuarine sediment to the lake central into the plot, in the early period of Spring $\mathrm{s}$ braided river delta sedimentary system; sedimentation basins remained stable $\mathrm{d}$ uring the gradual transition from a braided river delta deposited lacustrine sedim entary finally becomes meandering river sediments. 


\section{Acknowledgements}

Thanks Earth Sciences Professor Wang Wenguang my careful guidance and help, as well as Liu Chengzhi academic teacher gave me the instructions, they thought for flexible academic seriousness and research are worth learning, I insist on the academic path. Here I would like to pay tribute to mentor and heartfelt thanks! Task Force thanked the students and senior Shijie Men, my dorm roommate in learning and life has given me the care and help, this time graduate student life and learning, we have established a deep friendship, to express gratitude together. Thanks also to my younger brothers and sisters, and you have provided me with the help of many, to express sincere thanks.

\section{References}

[1] The history of Maria, Zhang Jinliang, Xu Shujuan, Wang Shan Zhang, Xiaoh ua, Yan'an environmental studies sedimentary rock Kau Ning Basin Jiyuan A rea [J]. China Ocean University (Natural Science) 2011 (10).

[2] Liu Taixun, Xuhuai Min. Fan delta reservoir simulation microscopic distribut ion of remaining oil test [J]. China University of Petroleum (Natural Science) 2011 (04).

[3] Rethinking Wang Hongliang, Zhou Tingchong whole, Song Jianyong, Miao d ragons sag west Paleogene sedimentary characteristics of the three sections o f sand and petroleum geological significance [J]. Modern Geology. 2011 (04)

[4] Deming built in Xinghe Cheng Yuehong, Linlin Zhang, Li Dongmei. Shulu S ec west slope of the sand reservoir distribution and accumulation pattern depr ession [J]. Special reservoir. 2011 (03).

[5] Xu Zhenping, Li Yong, MA Yu-jie, Wu Chao, Yangxian Zhang, Li Qing. Kuq a Depression tectonic units of the central division of the new program and ga s exploration direction [J]. Natural Gas Industry. 2011 (03).

[6] Zhao Columbians, Chen Deng Chao, Deng Jian, Jinping Li money -. Ejinaqi and adjacent areas Carboniferous - Permian carbonate rocks of sedimentary c 
haracteristics and its geological significance [J] Earth Sciences (China Unive rsity of Geosciences) 2011 (. 01).

[7] Young Elliott, Wang language, Fantai Liang, et pear rift sedimentary characteristics YINGCHENG Sujiatun area [J] Oil and Gas Geology, 2013,34 (3): 349-356.

[8] Zhang Xi, SONG Zhen ring, Xu, et Songliao Basin rift pear dynamic evaluation of oil and gas resources [J] petroleum geology experiment, 2013,35 (2): 224-230.

[9] King Fu Shan, Ge Daiwei, music Jianghua, Mary Yan Yan Chan, Guangyi industry, Liu Yan, Ji Wang Xia, LI Ming Basin southeast margin sequence stratigraphy and sedimentary system configuration and evolution [J] .2013 February .31 (1): 68-76.

[10] Liang Yang pear breaking research [J] Ssangyong second concave depression reservoir characteristics and hydrocarbon accumulation mode Guangdong Chemical Industry, 2013,40 (22).

[11] Do Campo M, Nieto F, Del Papa C, et al. Syn- and post-sedimentary controls on clay mineral assemblages in a tectonically active basin, Andean Argentinean foreland[J]. Journal of South American Earth Sciences. 2014, 52(0): 43-56.

[12] Li Baoyi, Wang Jianpeng, Xuyin Bo, organic-rich mudstone Sunping Chang test parameters and significance rift and sag basin $[\mathrm{J}]$ world geological, 2012,31 (4): 778-784.

[13] WANG Guo Shou Qi Qiu, Zhang Xinguo, pear and other Songliao Basin oilfield rift ten houses Yingcheng, Shahezi DIAGENESIS analysis [J] petroleum geology experiment, 2012,34 (5): 474 -480.

[14] Young Elliott, Wang language, Fantai Liang, et pear rift sedimentary characteristics YINGCHENG Sujiatun area [J] Oil and Gas Geology, 2013,34 (3): 349-356. 